\title{
Semi-refined carrageenan induces eryptosis in a Ca2+-dependent manner
}

\author{
Anton Tkachenko ${ }^{1,2}$, Volodymyr Prokopiuk ${ }^{1,3}$, Anatolii Onishchenko ${ }^{1,2}$ \\ ${ }^{1}$ Research Institute of Experimental and Clinical Medicine, Kharkiv National Medical University, Kharkiv, Ukraine \\ ${ }^{2}$ Department of Biochemistry, Kharkiv National Medical University, Kharkiv, Ukraine \\ ${ }^{3}$ Department of Cryobichemistry, Institute for Problems of Cryobiology and Cryomedicine of the National Academy of Sciences of Ukraine, Kharkiv, Ukraine
}

Received: 2021-11-19.

Accepted: 2021-12-24

This work is licensed under a Creative Commons Attribution 4.0 International License

J Clin Med Kaz 2022; 19(1):42-45

Corresponding author:

Anton Tkachenko.

E-mail: as.tkachenko@knmu.edu.ua;

ORCID: 0000-0002-1029-1636

\section{Abstract}

Background: Semi-refined carrageenan (food additive E407a) is a widely used thickener, which has been reported to exert toxic and proinflammatory effects. In particular, there is accumulating evidence that it induces eryptosis, i.e. a programmed cell death of eryptocytes, via ROSmediated pathways. However, the role of $\mathrm{Ca}^{2+}$-dependent mechanisms in E407a-induced eryptosis is not elucidated.

Material and methods: Semi-refined carrageenan at concentrations of $0 \mathrm{mg} / \mathrm{ml}, 1 \mathrm{mg} / \mathrm{ml}, 5 \mathrm{mg} / \mathrm{ml}$ and $10 \mathrm{mg} / \mathrm{ml}$ was incubated with blood of intact female WAG rats $(n=9)$ for $24 \mathrm{~h}$ in RPMI and fetal bovine serum. After $24 \mathrm{~h}$, the samples were used to obtain erythrocyte suspensions. The obtained suspensions were stained with a $\mathrm{Ca}^{2+}$-sensitive FLUO4 AM probe $(30 \mathrm{~min}, 2.5 \mu \mathrm{M})$. The fluorescence of FLUO4 in erythrocytes was detected by a BD FACSCanto II flow cytometer.

Results: The intracellular $\mathrm{Ca}^{2+}$ levels are proportional to the fluorescence of FLUO4. The mean fluorescence intensities (MFI) were compared. Low levels (1 $\mathrm{mg} / \mathrm{ml}$ ) of E407a had no impact on $\mathrm{Ca}^{2+}$ concentrations in erythrocytes ( $\left.p>0.05\right)$. On the contrary, high concentrations $(5 \mathrm{mg} / \mathrm{ml}$ and $10 \mathrm{mg} / \mathrm{ml}$ ) of this food additive promoted an increase in the intracellular $\mathrm{Ca}^{2+}$ levels. The MFI values were 2.3- and 2.5 -fold higher, respectively $(\mathrm{p}<0.0001)$. In addition, the exposure to E407a at concentrations of $5 \mathrm{mg} / \mathrm{ml}$ and $10 \mathrm{mg} / \mathrm{ml}(p<0.0001)$ increased the percentage of cells with high FLUO4 fluorescence.

Conclusion: Food additive E407a induces eryptosis in a $\mathrm{Ca}^{2+}$ dependent manner.

Key words: calcium ion, erythrocytes, food additives, FLUO4

\section{Introduction}

The lifespan of erythrocytes is approximately 120 days. After that period, they are eliminated from the bloodstream by the fixed macrophages. However, in response to unfavorable factors, including lack of energy, hyperosmolarity, accumulation of reactive oxygen species (ROS), they undergo cell death referred to as eryptosis $[1,2]$. In some ways, it resembles apoptosis of nucleuscontaining cells and is characterized by blebbing, shrinkage and plasma phospholipid membrane scrambling [3]. The activation of eryptosis is mediated by oxidative stress (ROS overproduction), elevation of intracellular calcium ions, ceramide formation, etc. [4]. The physiological aim of eryptosis is to prevent destruction of damaged cells by hemolysis, which is associated with membrane rupture and release of alarmins or damage-associated molecular patterns (DAMPs). Erythrocyte-derived DAMPs such as hemoglobin, ATP, interleukin-33 and heat shock protein 70 are strongly pro-inflammatory [5]. In addition to endogenous factors, eryptosis is induced by a plethora of xenobiotics, including drugs $[6,7]$.
Eryptosis contributes significantly to the pathophysiology of many diseases, since its activation is associated with the reduced lifespan of red blood cells and impaired blood clotting, which alters microcirculation [8]. Accelerated erythrocyte removal from the bloodstream via eryptosis favors the development of anemia in thalassemia [4], end stage renal disease [9], malaria [10], sickle cell anemia [2], etc. This suggests that the approaches used to manipulate eryptosis can be applied as therapeutic strategies in diseases associated with anemia [11].

It is important to note that nowadays eryptosis parameters are considered to be markers of biocompatibility and cytotoxicity [12-14]. In particular, eryptosis indices can be used to assess the cytotoxicity of food additives [15]. The safety of one of the numerous food additives available in the market called carrageenan, which is registered in EU countries as either E407 (refined or native carrageenan) or E407a (semi-refined carrageenan), is debating. Carragenans are thickeners and gelling agents whose share in the global food market has been increasing for decades. Their content in food 
and daily intake may vary significantly. In some dairy products, the content of carrageenan can reach up to $0.5 \%$ of weight [16]. According to some estimates, the amount of daily ingested carrageenan can be up to $7.2 \mathrm{~g}$ and this amount has been growing for years due to the prevalence of carrageenan-containing processed foods in Western diet [17]. However, carrageenans have been suggested to induce inflammation [16, 18-24]. The proinflammatory effects attributed to them contributed to setting up a programme for re-evaluating carrageenan safety for consumers (EFSA-Q-2018-00771). Controversial data on the findings of toxicity studies indicate that novel models for assessing the carrageenan safety are required. Semi-refined carrageenan has been shown to induce eryptosis in a dose-dependent way with the involvement of ROS-mediated pathways in activation of this cell death mode [15]. However, it is not clear whether this food additive can promote eryptosis via calcium-mediated pathways.

The aim of this study was to analyze the role of $\mathrm{Ca}^{2+}$ dependent mechanisms in eryptosis induced by the common food additive E407a.

\section{Materials and methods Incubation of E407a with blood}

Blood specimens were taken from nine intact adult female WAG rats weighing up to $200 \mathrm{~g}$. To ensure prevention of blood clotting, K2EDTA Vacutainers (IMPROVACUTER Evacuated EDTA K2 Spray Dried PET Tubes, Guangzhou, China) were used. Then blood samples $(50 \mu \mathrm{l})$ were incubated horizontally with $5 \mathrm{ml}$ RPMI-1640 medium with stable glutamine (Biowest, France) and 5\% fetal bovine serum (BioWhittaker ${ }^{\circledR}$, Lonza, Belgium) during $24 \mathrm{~h}$ in sterile SPL $15 \mathrm{ml}$ conical tubes. Four tubes were used per rat (E407a concentrations: $0 \mathrm{mg} / \mathrm{ml}, 1 \mathrm{mg}$ / $\mathrm{ml}, 5 \mathrm{mg} / \mathrm{ml}$ and $10 \mathrm{mg} / \mathrm{ml}$ ). After incubation, blood samples were centrifuged. Supernatants were discarded. Cell pellets were used to obtain erythrocyte suspensions, which was performed by double washing using phosphate buffer saline (PBS). Thereafter, $2 \mu \mathrm{l}$ of red blood cell mass was used for FLUO4 AM loading. The study design is demonstrated in Figure 1.

The study was carried out in conformity with the Directive 2010/63/EU for the Protection of Animals Used for Scientific Purposes and the European Convention for the Protection of Vertebrate Animals used for Experimental and other Scientific

Figure 1 - Diagram of the study design

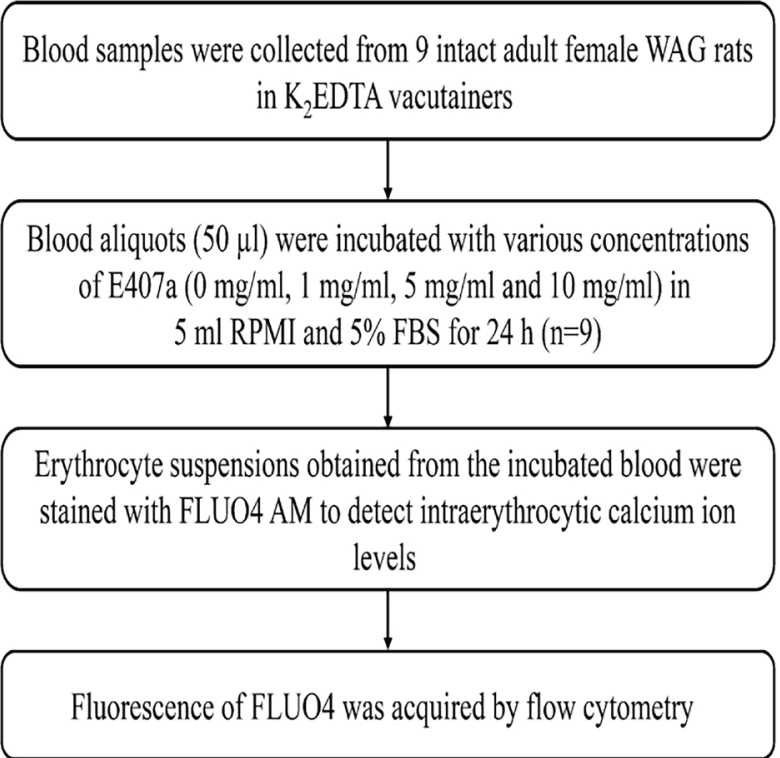

Purposes (EST 123). The Commission on Ethics and Bioethics (Kharkiv National Medical University, Kharkiv, Ukraine; minutes \#5 dated September 17, 2019) approved of the study.

\section{FLUO4 AM staining}

FLUO4 AM staining was used to assess intraerythrocytic $\mathrm{Ca}^{2+}$ levels by flow cytometry. FLUO4 AM dye powder purchased from Becton Dickinson (USA) was stored at $-20{ }^{\circ} \mathrm{C}$. Prior to the experiment, it was warmed up to room temperature and dissolved in anhydrous dimethyl sulfoxide (Sigma Aldrich, USA) to obtain $5 \mathrm{mM}$ stock solution. The stock solution was used to stain erythrocyte suspensions containing $2 \mu$ of erythrocytes incubated with various concentrations of E407a and $98 \mu \mathrm{l}$ PBS. The final concentration of $\mathrm{Ca}^{2+}$-sensitive probe in working solutions was $2.5 \mu \mathrm{M}$. The FLUO4-loaded erythrocyte suspensions were incubated in the dark for $30 \mathrm{~min}$. Then 400 $\mu 1$ PBS was added to each tube. Fluorescence was acquired by BD FACSCanto ${ }^{\mathrm{TM}}$ II system. In each sample, 300000 events were collected. The fluorescence of FLUO4 was analyzed (FL1 $=530 / 30 \mathrm{BP})$. Erythrocyte suspensions with no added FLUO4 were used as negative controls. Hydrogen peroxide-treated $(0.1$ $\mathrm{mM}$ ) erythrocytes were used as positive controls.

\section{Statistical analysis}

The Shapiro-Wilk test allowed assessing the distribution normality. Four independent invariables were compared using the Kruskal-Wallis and post-hoc Dunn's tests. The mean fluorescence intensities (MFI) of FLUO4 were represented as the median (Me) and interquartile range (IQR; 25\%-75\%) with $\mathrm{p}$ values below 0.05 considered statistically significant. All statistical calculations were performed with Graph Pad Prism 5.0 (USA).

\section{Results}

Since calcium release into the cytosol of erythrocytes plays a pivotal role in induction of eryptosis, its concentration in red blood cells exposed to E407a was determined by FLUO4 staining. Quantitatively, intracellular $\mathrm{Ca}^{2+}$ levels were estimated by comparing MFI values of FLUO4, which depend on $\mathrm{Ca}^{2+}$ concentrations, and the percentage of erythrocytes with the increased FLUO4 fluorescence.

Representative histograms and MFI values of FLUO4 in all the studies groups of samples are shown in Figures 2 and 3.

Figure 2 - Representative side scatter (SSC) \& green fluorescence (FL1) histograms demonstrate a more intense fluorescence of FLUO4 in erythrocytes exposed to the highest concentrations of semi-refined carrageenan (E407a)

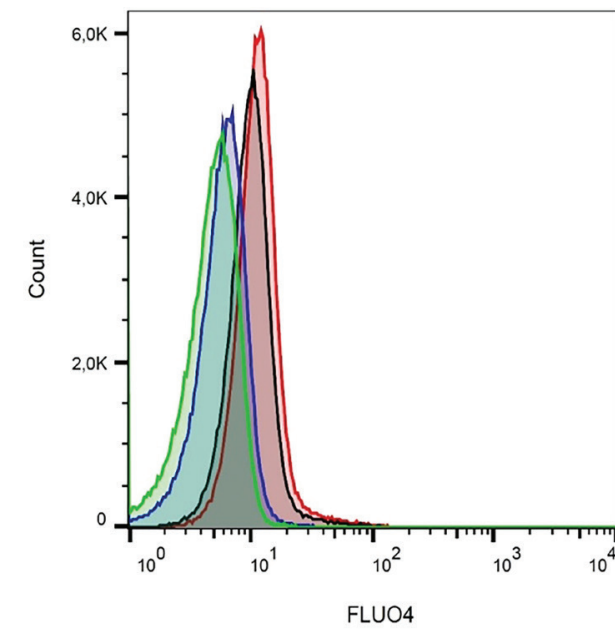


Figure 3 - Mean fluorescence intensity (MFI) values of FLUO4 in red blood cells treated with semi-refined carrageenan (E407a) reflect the intracellular calcium ion levels

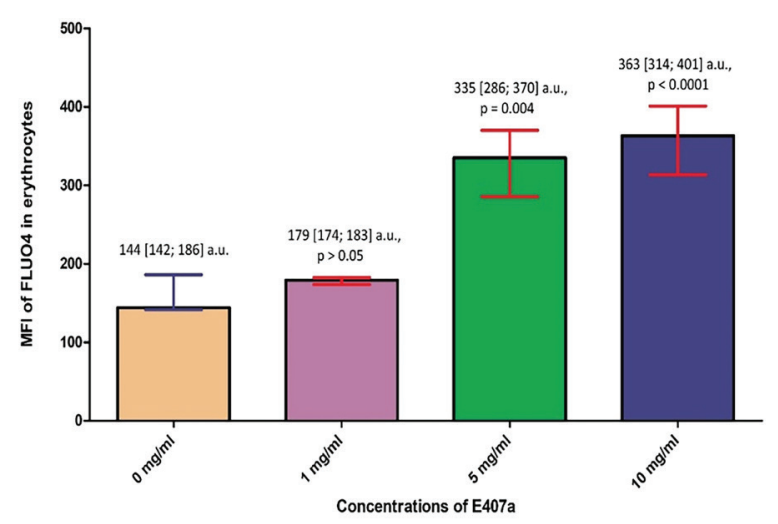

The lowest concentration of semi-refined carrageenan, i.e. $1 \mathrm{mg} /$ $\mathrm{ml}$ did not promote the elevated FLUO4 fluorescence, evidenced by no statistically significant changes in MFI values of FLUO4 $(\mathrm{p}=0.25)$. At the same time, a 2.3-fold elevation of this index was observed in response to $5 \mathrm{mg} / \mathrm{ml}(\mathrm{p}=0.004)$. The highest amount of semi-refined carrageenan used in this study $(10 \mathrm{mg} /$ $\mathrm{ml}$ ) increased FLUO4 fluorescence over 2.5 times, $\mathrm{p}<0.0001$ (Figure 3).

In addition to the MFI values of FLUO4, we analyzed the amount of erythrocytes with high FLUO4 fluorescence. Low levels of E407a (1 mg/ml) were revealed to have no effects on this parameter $(\mathrm{p}>0.05)$, whereas an increase in the concentration of this food additive promoted the increase in the percentage of such cells either 14.6-fold (5 mg/ml) or 20.2-fold $(10 \mathrm{mg} /$ $\mathrm{ml})$. These data are represented in Figure 4. It should be noted that the difference is statistically significant $(p<.0001)$. Thus, changes in both parameters of FLUO4 fluorescence indicate an increase in the intracellular $\mathrm{Ca}^{2+}$ levels in erythrocytes exposed to over $5 \mathrm{mg} / \mathrm{ml} \mathrm{E} 407 \mathrm{a}$.

\section{Discussion}

Reports on the mechanism of carrageenan toxicity are multiple, but controversial. There is accumulating evidence that pro-inflammatory effects of E407a are mediated by TLR4 (toll-like receptor 4) signaling, NF-kB (nuclear factor kappa light chain enhancer of activated $\mathrm{B}$ cells) transcription factor, ROS-activated pathways and NLRP3 (NOD-, LRR- and pyrin domain-containing protein 3) inflammasome activation [2527]. All these pathways eventually result in the upregulation of pro-inflammatory cytokines. However, in red blood cells the pathways outlined above are either absent or their role differs. These facts make erythrocytes a useful tool for evaluating the toxicity of xenobiotics.

It has been recently reported that carrageenans have proeryptotic activities, evidenced by phosphatidylserine exposure on the surface of cells and excessive ROS production [15]. However, no data on the ability of dietary high-molecular-weight carrageenans to activate $\mathrm{Ca}^{2+}$-mediated pathways in red blood cells or other types of host cells are available. This is especially interesting given the crucial role of calcium ions in eryptosis. In particular, increased intraerythrocytic calcium concentration promotes phosphatidylserine translocation to the outer leaflet of cell membrane influencing the activity of scramblases [28].

Eryptosis indices estimated in this study indicate that semi-refined carrageenan significantly increased intracellular $\mathrm{Ca}^{2+}$ concentrations, which leads to activation of eryptosis.
Figure 4 - The amount of cells with enhanced FLUO4 fluorescence after exposure to semi-refined carrageenan (E407a)

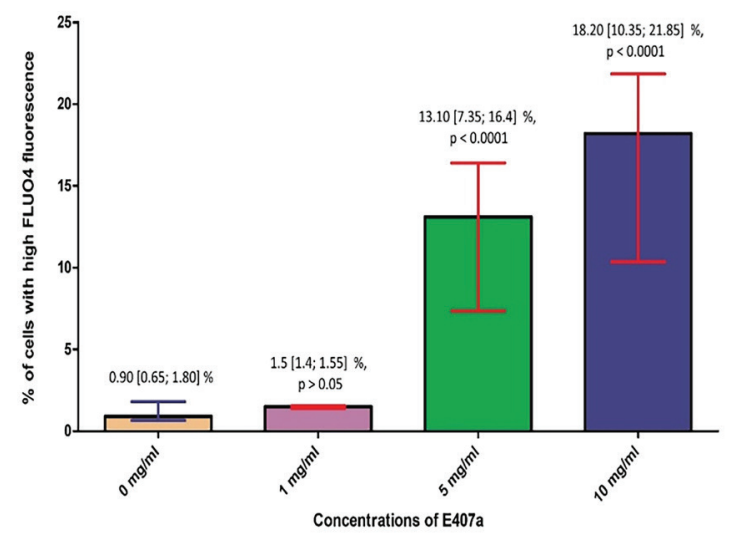

When comparing with the data on ROS overproduction in erythrocytes exposed to the same concentrations of E407a, the ability of E407a to increase $\mathrm{Ca}^{2+}$ levels in red blood cells is more pronounced [15]. Thus, pro-eryprotic effects of carrageenans can be primarily ascribed to $\mathrm{Ca}^{2+}$-mediated damage. This conclusion is quite unexpected due to the multiple reports on pro-oxidant activities of carrageenans, their ability to induce ROS production and oxidative stress [18, 25, 27, 29, 30]. In addition, it is important to note that our findings are consistent with other data that suggest the dose-dependent cytotoxicity of carrageenans. In particular, the same semi-refined carrageenan is demonstrated to increase the metabolic activity and reduce the motility of fibroblasts at concentrations of over $5 \mathrm{mg} / \mathrm{ml}$ [31].

Thus, this study contributes to revealing the molecular mechanisms for carrageenan-mediated toxicity by demonstrating the ability of E407a to induce intracellular $\mathrm{Ca}^{2+}$ levels. However, more research efforts should be made to close the knowledge gap on the molecular targets and pro-inflammatory pathways activated by carrageenans.

The study has several strengths. Firstly, FLUO4 AM staining with data acquisition via flow cytometry is a widely recognized and modern technique to assess intracellular $\mathrm{Ca}^{2+}$ levels. Secondly, two parameters for FLUO4 fluorescence were used. Thirdly, simple experimental design can be easily replicated. The study limitations include: application of only one method to assess intracellular $\mathrm{Ca}^{2+}$ levels; human erythrocytes were not used.

\section{Conclusion}

Semi-refined carrageenan (E407a) promotes eryptosis in a $\mathrm{Ca}^{2+}$-dependent manner.

Disclosures: There is no conflict of interest for all authors.

Acknowledgements: The authors express sincere gratitude to all colleagues who have contributed to this study in any way.

The research was carried out as a fragment of the research entitled "Biochemical Mechanisms for the Induction of Intestinal Inflammation and the Ways of its Correction (Kharkiv National Medical University, Kharkiv, Ukraine; state registration number 0120U102645).

Funding: None. 


\section{References}

1. Pretorius E, du Plooy JN, Bester J. A Comprehensive Review on Eryptosis. Cell Physiol Biochem. 2016;39(5):1977-2000. https://doi. org/10.1159/000447895

2. Lang F, Lang KS, Lang PA, Huber SM, Wieder T. Mechanisms and significance of eryptosis. Antioxid Redox Signal. 2006;8(7-8):118392. https://doi.org/10.1089/ars.2006.8.1183

3. Lang F, Lang E, Föller M. Physiology and pathophysiology of eryptosis. Transfus Med Hemother. 2012;39(5):308-14. https://doi. org/10.1159/000342534

4. Bissinger R, Bhuyan AAM, Qadri SM, Lang F. Oxidative stress, eryptosis and anemia: a pivotal mechanistic nexus in systemic diseases. FEBS J. 2019;286(5):826-854. https://doi.org/10.1111/febs.14606

5. Jeney V. Pro-Inflammatory Actions of Red Blood Cell-Derived DAMPs. Exp Suppl. 2018;108:211-233. https://doi.org/10.1007/978-3319-89390-7 9

6. Alfhili MA, Weidner DA, Lee MH. Disruption of erythrocyte membrane asymmetry by triclosan is preceded by calcium dysregulation and p38 MAPK and RIP1 stimulation. Chemosphere. 2019;229:103-111. https://doi.org/10.1016/j.chemosphere.2019.04.211

7. Al Mamun Bhuyan A, Nüßle S, Cao H, Zhang S, Lang F. Simvastatin, a Novel Stimulator of Eryptosis, the Suicidal Erythrocyte Death. Cell Physiol Biochem. 2017;43(2):492-506. https://doi.org/10.1159/000480476

8. Qadri SM, Bissinger R, Solh Z, Oldenborg PA. Eryptosis in health and disease: A paradigm shift towards understanding the (patho) physiological implications of programmed cell death of erythrocytes. Blood Rev. 2017;31(6):349-361. https://doi.org/10.1016/j. blre.2017.06.001

9. Lang F, Bissinger R, Abed M, Artunc F. Eryptosis - the Neglected Cause of Anemia in End Stage Renal Disease. Kidney Blood Press Res. 2017;42(4):749-760. https://doi.org/10.1159/000484215

10. Totino PRR, de Souza HADS, Correa EHC, Daniel-Ribeiro CT, Ferreira-da-Cruz MF. Eryptosis of non-parasitized erythrocytes is related to anemia in Plasmodium berghei low parasitema malaria of Wistar rats. Parasitol Res. 2019;118(1):377-382. https://doi.org/10.1007/ s00436-018-6167-1

11. Boulet C, Doerig CD, Carvalho TG. Manipulating Eryptosis of Human Red Blood Cells: A Novel Antimalarial Strategy? [published correction appears in Front Cell Infect Microbiol. 2019 Jan 14;8:455]. Front Cell Infect Microbiol. 2018;8:419. https://doi.org/10.3389/ fcimb.2018.00419

12. Onishchenko A, Myasoedov V, Yefimova S, Nakonechna O, Prokopyuk V, Butov D, et al. UV Light-Activated GdYVO4:Eu3+ Nanoparticles Induce Reactive Oxygen Species Generation in Leukocytes Without Affecting Erythrocytes In Vitro. Biol Trace Elem Res. 2021. https://doi.org/10.1007/s12011-021-02867-z

13. Ran Q, Xiang Y, Liu Y, Xiang L, Li F, Deng X, et al. Eryptosis Indices as a Novel Predictive Parameter for Biocompatibility of Fe3O4 Magnetic Nanoparticles on Erythrocytes. Sci Rep. 2015;5:16209. https://doi.org/10.1038/srep16209

14. Pagano M, Faggio C. The use of erythrocyte fragility to assess xenobiotic cytotoxicity. Cell Biochem Funct. 2015;33(6):351-5. https:// doi.org/10.1002/cbf.3135

15. Tkachenko A, Kot Y, Prokopyuk V, Onishchenko A, Bondareva A, Kapustnik V, et al. Food additive E407a stimulates eryptosis in a dose-dependent manner. Wien Med Wochenschr. 2021. https://doi.org/10.1007/s10354-021-00874-2

16. David S, Shani Levi C, Fahoum L, Ungar Y, Meyron-Holtz EG, Shpigelman A, et al. Revisiting the carrageenan controversy: do we really understand the digestive fate and safety of carrageenan in our foods? Food Funct. 2018;9(3):1344-1352. https://doi.org/10.1039/ c7fo01721a

17. Bhattacharyya S, Shumard T, Xie H, Dodda A, Varady KA, Feferman L, et al. A randomized trial of the effects of the no-carrageenan diet on ulcerative colitis disease activity. Nutr Healthy Aging. 2017;4(2):181-192. https://doi.org/10.3233/NHA-170023

18. Liu F, Hou P, Zhang H, Tang Q, Xue C, Li RW. Food-grade carrageenans and their implications in health anddisease. Compr Rev Food Sci Food Saf. 2021:1-19. https://doi.org/10.1111/1541-4337.12790

19. Pogozhykh D, Posokhov Y, Myasoedov V, Gubina-Vakulyck G, Chumachenko T, Knigavko O, et al. Experimental Evaluation of FoodGrade Semi-Refined Carrageenan Toxicity. Int J Mol Sci. 2021;22(20):11178. https://doi.org/10.3390/ijms222011178

20. Tkachenko AS, Kot YG, Kapustnik VA, Myasoedov VV, Makieieva NI, Chumachenko TO, et al. Semi-refined carrageenan promotes generation of reactive oxygen species in leukocytes of rats upon oral exposure but not in vitro. Wien Med Wochenschr. 2021;171(34):68-78. https://doi.org/10.1007/s10354-020-00786-7

21. Younes M, Aggett P, Aguilar F, Crebelli R, Filipič M, Frutos MJ, et al. Re-evaluation of carrageenan (E 407) and processed Eucheuma seaweed (E 407a) as food additives. EFSA J. 2018;16(4):e05238. https://doi.org/10.2903/j.efsa.2018.5238

22. Gubina-Vakyulyk GI, Gorbach TV, Tkachenko AS, Tkachenko MO. Damage and regeneration of small intestinal enterocytes under the influence of carrageenan induces chronic enteritis. Comparative Clinical Pathology. 2015;24(6):1473-1477. https://doi.org/10.1007/ s00580-015-2102-3

23. Necas J, Bartosikova L. Carrageenan: a review. Veterinarni Medicina. 2013;58:187-205.

24. Tobacman JK. Review of harmful gastrointestinal effects of carrageenan in animal experiments. Environ Health Perspect. 2001;109(10):983-94. https://doi.org/10.1289/ehp.01109983

25. Lopes AH, Silva RL, Fonseca MD, Gomes FI, Maganin AG, Ribeiro LS, et al. Molecular basis of carrageenan-induced cytokines production in macrophages. Cell Commun Signal. 2020;18(1):141. https://doi.org/10.1186/s12964-020-00621-x

26. Myers MJ, Deaver CM, Lewandowski AJ. Molecular mechanism of action responsible for carrageenan-induced inflammatory response. Mol Immunol. 2019;109:38-42. https://doi.org/10.1016/j.molimm.2019.02.020

27. Bhattacharyya S, Dudeja PK, Tobacman JK. Carrageenan-induced NFkappaB activation depends on distinct pathways mediated by reactive oxygen species and Hsp27 or by Bcl10. Biochim Biophys Acta. 2008;1780(7-8):973-982. https://doi.org/10.1016/j. bbagen.2008.03.019

28. Bigdelou P, Farnoud AM. Induction of Eryptosis in Red Blood Cells Using a Calcium Ionophore. J Vis Exp. 2020;(155):10.3791/60659. https://doi.org/10.3791/60659

29. Sokolova EV, Menzorova NI, Davydova VN, Kuz'mich AS, Kravchenko AO, Mishchenko NP, et al. Effects of Carrageenans on Biological Properties of Echinochrome. Mar Drugs. 2018;16(11):419. https://doi.org/10.3390/md16110419

30. Barth CR, Funchal GA, Luft C, de Oliveira JR, Porto BN, Donadio MV. Carrageenan-induced inflammation promotes ROS generation and neutrophil extracellular trap formation in a mouse model of peritonitis. Eur J Immunol. 2016;46(4):964-70. https://doi.org/10.1002/ eji.201545520

31. Tkachenko A, Prokopiuk V, Onishchenko A, Shevchenko M. Effects of E407a on the viability, metabolic and functional activity of dermal fibroblasts. J Clin Med Kaz. 2021;18(5):49-53. https://doi.org/10.23950/jcmk/11229 